\title{
Effect of Saccharomyces cerevisiae var. Boulardii and $\beta$-galactomannan oligosaccharide on porcine intestinal epithelial and dendritic cells challenged in vitro with Escherichia coli F4 (K88)
}

Roger Badia ${ }^{1,3^{*}}$, Galliano Zanello², Claire Chevaleyre ${ }^{2}$, Rosil Lizardo', François Meurens², Paz Martínez³, Joaquim Brufau ${ }^{1 *}$ and Henri Salmon ${ }^{2}$

\begin{abstract}
Probiotic and prebiotics, often called "immune-enhancing" feed additives, are believed to deal with pathogens, preventing the need of an immune response and reducing tissue damage. In this study, we investigated if a recently developed $\beta$-galactomannan ( $\beta G M)$ had a similar protective role compared to Saccharomyces cerevisiae var. Boulardii (Scb), a proven probiotic, in the context of enterotoxigenic Escherichia coli (ETEC) infection. ETEC causes inflammation, diarrhea and intestinal damage in piglets, resulting in large economic loses worldwide. We observed that $S c b$ and $\beta G M$ products inhibited in vitro adhesion of ETEC on cell surface of porcine intestinal IPI-2I cells. Our data showed that $S c b$ and $\beta G M$ decreased the mRNA ETEC-induced gene expression of pro-inflammatory cytokines TNF- $\alpha$, IL-6, GM-CSF and chemokines CCL2, CCL20 and CXCL8 on intestinal IPI-2I. Furthermore, we investigated the putative immunomodulatory role of $S c b$ and $\beta G M$ on porcine monocyte-derived dendritic cells (DCs) per se and under infection conditions. We observed a slight up-regulation of mRNA for TNF- $\alpha$ and CCR7 receptor after coincubation of DC with Scb and $\beta G M$. However, no differences were found in DC activation upon ETEC infection and $S c b$ or $\beta G M$ co-culture. Therefore, our results indicate that, similar to probiotic $S c b$, prebiotic $\beta G M$ may protect intestinal epithelial cells against intestinal pathogens. Finally, although these products may modulate DC activation, their effect under ETEC challenge conditions remains to be elucidated.
\end{abstract}

\section{Introduction}

The infection by enterotoxigenic Escherichia coli (ETEC) is one on the most important causes of neonatal and postweaning diarrhea (PWD) in piglets. ETEC causes significant morbidity and mortality, resulting in a large economic loses in the porcine industry. One of the most common ETEC in swine is serotype 0149 which carries the K88 (F4) adhesin that enables the attachment of the bacteria to the intestinal epithelium. ETEC colonizes ileum $[1,2]$, penetrate the epithelium and its pathogenesis is ascribed to the production of different combination of heat-labile (LT) and heat-stable (ST) enterotoxins [3,4].

\footnotetext{
* Correspondence: roger.badia@irta.cat; joaquim.brufau@irta.cat 'Institut de Recerca i Tecnologia Agroalimentàries, Animal Production, IRTA, Constantí, Spain

Full list of author information is available at the end of the article
}

Antibiotic growth promoters (AGPs) have been long used in animal feeding to prevent neonatal and PWD in piglets. The use of AGPs increases the prevalence of bacteria resistant to antibiotics in farm animals and constitutes a potential risk of antibiotic resistance transference to human pathogenic bacteria, following to consumption of animal derived products [5]. The European ban of AGPs in animal production (EC 1831/ 2003) increased the need to develop new alternatives [6] to control and prevent animal colonization by pathogenic bacteria and somehow guarantee animal welfare and food safety.

Probiotics and prebiotics are interesting alternatives to AGP for animal feeding. They are believed to control pathogenic bacteria colonization and to enhance the mucosal immune system, resulting in a decreased pathogenic load and improving animal welfare [7]. The yeast
C Biomed Central

() 2012 Badia et al; licensee BioMed Central Ltd. This is an Open Access article distributed under the terms of the Creative Commons Attribution License (http://creativecommons.org/licenses/by/2.0), which permits unrestricted use, distribution, and reproduction in any medium, provided the original work is properly cited. 
Saccharomyces cerevisiae var. Boulardii $(S c b)$ is a wellknown probiotic with proven effects for the treatment and prevention of gastrointestinal diseases (see [8] for review). Typically, between 30-60\% of Saccharomyces yeast wall is composed by polysaccharides [9] and specifically mannose and galactose mannans represent respectively more than $50 \mu \mathrm{g} / \mathrm{mg}$ of yeast dry mass [10]. Our center (Institut de Recerca i Tecnologia Agroalimentàries, IRTA) developed a highly rich $\beta$-galactomannan prebiotic $(\beta G M)$ from the carob bean of the Ceratonia silliqua tree that as non-digestible food prebiotic ingredient may beneficially affect the host.

Intestinal epithelial cells (IECs) and dendritic cells (DC) of the gut are crucial for maintaining immunological tolerance to environmental, food antigens and commensal bacteria, but also to develop strong responses to invading pathogens when required $[11,12]$. Recent studies have demonstrated that IECs are far from being a simple physical barrier to the external environment. Pathogen associated molecular patterns (PAMPS) are recognized by Pattern recognition receptors (PRRs), such as Toll-like receptors (TLRs), expressed on IECs membranes [13], leading to the activation of proinflammatory pathways, as nuclear factor $-\kappa \mathrm{B}(\mathrm{NF}-\kappa-\mathrm{B})$ and activator protein 1 (AP1), related to cytokines and chemokines that coordinate the innate immune response [14].

Our work intended to establish an in vitro screening of an already known probiotic $(S c b)$ and new developed prebiotic $(\beta \mathrm{GM})$ to promote their use in animal feeding. First, we focused on antimicrobial activity and bacterial adhesion studies of these products on the IECs and how they may enhance an effective maintenance of the intestinal barrier. Furthermore, we studied their ability to modulate DCs which are pivotal for linking innate and adaptive immune response against pathogens. We were especially interested in the role of both cells types in cytokine and chemokine networks that regulate the homeostasis in the gastrointestinal tract [15].

\section{Materials and methods}

\section{Intestinal epithelial cell culture}

The porcine small intestine epithelial cell line IPI-2I (ECACC 93100622) was established from the ileum of an adult boar (SLAd/d haplotype) [16]. IPI-2I cells were maintained in DMEM (Invitrogen, Cergy Pontoise, France) supplemented with 10\% FCS (Sigma-Aldrich, Saint-Quentin, France), 4 mM L-glutamine (Invitrogen), insulin $10 \mu \mathrm{g} / \mathrm{mL}$ (Sigma-Aldrich), $100 \mathrm{U} / \mathrm{mL}$ penicillin and $100 \mu \mathrm{g} / \mathrm{mL}$ streptomycin (Invitrogen). In all experiments, cells were cultured in 6-well plates (Falcon) to confluence. Before the addition of pre/probiotics and/or infection, cells were washed three times to remove antibiotics and culture media was replaced by DMEM media (Invitrogen) containing $4 \mathrm{mM}$ L-glutamine (Invitrogen) and insulin $10 \mu \mathrm{g} / \mathrm{mL}$ (Sigma-Aldrich). Cells were used between passages 30-50 and periodically tested to avoid Mycoplasma contamination (MycoAlert ${ }^{\circledR}$ Mycoplasma Detection Kit, Lonza).

\section{Probiotic and prebiotic preparation}

Lyophilized Saccharomyces cerevisiae var. Boulardii (Scb, Biocodex, Laboratoires Montrouge, France) was rehydrated with $10 \mathrm{~mL}$ of DMEM and incubated for $30 \mathrm{~min}$ at $30^{\circ} \mathrm{C}$. Then, yeast was counted with a Neubauer cell counter and methyl blue to exclude non-viable yeast. The yeast was added to the selected wells (multiplicity of infection, $\mathrm{MOI}=3$ ) and incubated overnight at $37^{\circ} \mathrm{C}$ and $10 \% \mathrm{CO}_{2}$.

Commercially prebiotic Salmosan ${ }^{\circledR}$ (patent WO2009/ 144070 A2, licensed by Industrial Técnica Pecuaria, ITPSA, Barcelona, Spain) contains more than $98 \%$ of $\beta$ galactomannan $(\beta G M)$ which is a $\beta-(1-4)$-mannose backbone with branched galactose molecules (ratio galactose: mannose 1:4) [17]. Commercially prebiotic Salmosan ${ }^{\circledR}$ also contain less than $1 \%$ of other polysaccharides such as xylose, fructose, arabinose, glucose, galactosamine and fucose derived from the carob bean gum and the seed of the Ceratonia silliqua tree. This is product is industrially treated to become soluble in gut. $\beta$ GM is was diluted in DMEM $(1 \mathrm{mg} / \mathrm{mL})$, homogenized and incubated $30 \mathrm{~min}$ at $37^{\circ} \mathrm{C}$. Immediately before the infection, $\beta \mathrm{GM}$ was added to each well at $10 \mu \mathrm{g} / \mathrm{mL}$.

\section{Host cell-pathogen assay}

Two pathogenic E.coli K88 (ETEC) strains were used in the host-pathogen assays. Initially, ETEC $56190 \mathrm{~F}^{+}$ (K88ad, O8:K87:H19, $\mathrm{LT}^{+}$and $\mathrm{STb}^{+}$) from INRA collection was used for cytokine and chemokine mRNA assays. For adhesion assays and cytokine protein secre-

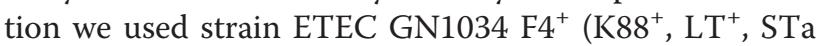
${ }^{+}$and $\mathrm{STb}^{+}$) provided by Dr Ignacio Badiola (Centre de Recerca en Sanitat Animal,CReSA, IRTA-UAB, Spain) which was more adherent to IPI-2I cells [18]. Both ETEC strains were preserved frozen in glycerol $15 \%$ at $-80^{\circ} \mathrm{C}$ until their use. Before infection, $50 \mu \mathrm{L}$ of ETEC were added to $20 \mathrm{~mL}$ of Luria-Bertrani media (LB) and cultured for $3-4 \mathrm{~h}$ at $37^{\circ} \mathrm{C}$ with $180 \mathrm{rpm}$ rotational agitation (Multitron HT, Infors). For the infection, ETEC was used at exponential growth phase by determination of absorbance at $600 \mathrm{~nm}$. ETEC was used at MOI $=10$, previously determined by cytotoxic lactate dehydrogenase activity assay (Cytotoxicity Detection Kit Plus LDH, Roche). In vitro challenge lasted $3 \mathrm{~h}$ for gene expression and bacterial adherence studies or $24 \mathrm{~h}$ for supernatant cytokine determination. After host cell-pathogen co-culture, cells or supernatants were respectively sampled and stored until their analysis. 


\section{Bacterial adherence assay}

Protective effect of $S c b$ and $\beta$ GM was assessed by the adherence assay of ETEC on IPI-2I cells. Protocol was previously described by [19]. After the host-pathogen assay, supernatant was removed and cells were washed twice with sterile PBS to eliminate all non-adhered bacteria. Then, cells were homogenized with $1 \mathrm{~mL}$ of $0.1 \%$ Triton $\times 100$ (Sigma-Aldrich) for $15 \mathrm{~min}$. This solution was serially diluted in PBS and $100 \mu \mathrm{L}$ (dilution $1 \times 10^{-}$ ${ }^{3}$ ) was plated in LB-Agar Petri dishes for $24 \mathrm{~h}$ at $37^{\circ} \mathrm{C}$ to enumerate the number of colony former units (CFU). The ability of ETEC GN1034 strain to adhere to IPI-2I cells was calculated as follows:

$$
\text { Adherence }(\%)=\frac{\text { Adhered ETEC to IECs }}{\text { Total ETEC added } / \text { well }} \times 100
$$

To determine adherence differences between experimental treatments, the relative percentage of adherence was calculated using next equation:

$$
\text { Relative adherence }(\%)=\frac{\mathrm{CFU} / \mathrm{ml} \text { treatment }}{\mathrm{CFU} / \mathrm{ml} \text { control infection }} \times 100
$$

\section{Isolation of mRNA and CDNA synthesis}

Total RNA was isolated from homogenized cells using Trizol reagent (Invitrogen) and RNeasy MiniKit (Qiagen, Courtaboeuf, France). Then, RNA samples were treated with DNase I Amp Grade (Invitrogen) (1 U/ $\mu$ g of RNA). RNA concentration was determined by measuring optical density at $260 \mathrm{~nm}$ (OD260) and the RNA quality was assessed by calculating OD260/OD280 ratio and by capillary electrophoresis (Agilent 2100 Bioanalyzer, Agilent Technologies Inc., Santa-Clara, USA). A total of $1 \mu \mathrm{g}$ of RNA was incubated in a final volume of $20 \mu \mathrm{L}$ containing $2 \mu \mathrm{L}$ dNTP (0.25 mM final each), $1.3 \mu \mathrm{L}$ oligodT (133 pmoles $/ \mu \mathrm{L}), 0.8 \mu \mathrm{L}$ MuMLV reverse transcriptase ( $25 \mathrm{U} /$ $\mu \mathrm{L}), 4 \mu \mathrm{L} 5 \times$ MuMLV buffer (Eurogentec, Liège, Belgium) and $1.9 \mu \mathrm{L}$ of ultra-pure water (Gibco, Paisley, Scotland). The reaction was maintained for $90 \mathrm{~min}$ at $37^{\circ} \mathrm{C}$ and then heat-inactivated at $93^{\circ} \mathrm{C}$ for $5 \mathrm{~min}$. The generated cDNA was stored at $-80^{\circ} \mathrm{C}$.

\section{Messenger RNA expression analysis using quantitative real-time PCR}

Many mRNA and primer sequences have already been identified in pigs [20-22]. When genes were not described in this species, tBLASTn searches of the GenBank and PEDEblast ESTs databases, using known human and murine amino acid sequences, have been performed. These primers (purchased from Eurogentec) allowed the mRNA expression analysis of various genes involved in the innate immune response (Table 1). The qPCR was performed using cDNA synthesized as previously described [23]. Diluted cDNA (10X) was combined with primer/probe sets and IQ SYBR Green Supermix (BioRad, Hercules, CA, USA) according to the manufacturer's recommendations. The qPCR conditions were $98^{\circ} \mathrm{C}$ for $30 \mathrm{~s}$, followed by 37 cycles with denaturation at $95^{\circ} \mathrm{C}$ for $15 \mathrm{~s}$ and annealing/elongation for $30 \mathrm{~s}$ (annealing temperature, Table 1). Real time assays were run on a BioRad Chromo4 (Bio-Rad). The specificity of the qPCR reactions was assessed by analyzing the melting curves of the products and size verification of the amplicons. Each qPCR reaction included a reverse transcription negative control (RNA sample without reverse transcriptase) to check the absence of genomic DNA. To minimize sample variation, we used identical number of cells and high quality RNA. Samples were normalized internally using simultaneously the average cycle threshold $(\mathrm{Cq})$ of Hypoxanthine PhosphoRibosyl-Transferase 1 (HPRT-1), Ribosomal Protein L 19 (RPL-19) and Tata Box Binding Protein 1 (TBP-1) [24] as references in each sample to avoid any artifact of variation in the target gene. These genes were selected as the reference genes because of their low variation between samples. A standard curve was generated using diluted cDNA. The correlation coefficients of the standard curves were $>0.995$ and the concentrations of the test samples were calculated from the standard curves, according to the formula $\mathrm{y}=-\mathrm{M} \times \mathrm{Cq}+$ $\mathrm{B}$, where $\mathrm{M}$ is the slope of the curve, $\mathrm{Cq}$ the point during the exponential phase of amplification in which the fluorescent signal is first recorded as being statistically significant above background and $\mathrm{B}$ the $\mathrm{y}$-axis intercept. $\mathrm{Cq}$ values were used to calculate the qPCR efficiency from the given slope according to the equation: qPCR efficiency $=(10[-1 / \mathrm{M}]-1) \times 100$. All qPCRs displayed efficiency between $90 \%$ and $110 \%$. Expression data are expressed as relative values after Genex macro-analysis with three reference genes (Bio-Rad, Hercules, USA) [25].

\section{Determination of cytokine production}

Cytokine protein determination in the culture supernatant was performed by enzyme-linked immunosorbent assays (ELISAs). Host cell-pathogen assay was performed as described above but to avoid bacterial overgrowth Gentamycin $100 \mu \mathrm{g} / \mathrm{mL}$ (Sigma-Aldrich) was added to each well. Cell culture supernatant was collected after $24 \mathrm{~h}$ and stored at $-80^{\circ} \mathrm{C}$ until analysis. Swine IL-6 and CXCL8 DuoSet ELISA from R\&D Systems (Vitro SP, Spain) were used according to manufacturer's recommendations.

\section{Isolation of peripheral blood monocytes and} differentiation of monocyte derived dendritic cells

Blood samples were obtained from 6 to 12-month old large white pigs at the slaughter house. Blood was collected into heparinised tubes and followed the protocol 
Table 1 Primer sequences and annealing temperatures of primer sets $\left({ }^{\circ} \mathrm{C}\right)$, expected PCR fragment sizes (bp) and associated references.

\begin{tabular}{|c|c|c|c|c|c|c|}
\hline Genes & Sense & Antisense & $\mathrm{T}^{\circ}$ Annealing & Product length & $\begin{array}{c}\text { Accession } \\
\text { Number }\end{array}$ & Reference \\
\hline$\overline{\text { APRIL }}$ & TGCTCACCCGTAAACAGAAG & TAAACTCCAGCATCCCAGAC & 60 & 172 & EST BP170456 & {$[21]$} \\
\hline BAFF & GAGAGCAGCTCCATTCAAAG & GCATGCCACTGTCTGCAATC & 60 & 103 & NM_001097498 & {$[21]$} \\
\hline $\mathrm{CCL} 2$ & GTCACCAGCAGCAAGTGTC & CCAGGTGGCTTATGGAGTC & 60 & 112 & EF107669 & [43] \\
\hline CCL17 & TGCTGCTCCTGGTTGCTCTC & ATGGCGTCCCTGGTACACTC & 67 & 169 & EST DB794536 & [20] \\
\hline CCL20 & GCTCCTGGCTGCTTTGATGTC & CATTGGCGAGCTGCTGTGTG & 66 & 146 & NM 001024589 & [21] \\
\hline CCR7 & AGGAGGCTCAAGACCATGAC & GATGCCGAAGATGAGTTTGC & 62 & 147 & AB090356 & \\
\hline CXCL2 & TGCTGCTCCTGCTTCTAGTG & TGGCTATGACTTCCGTTTGG & 60 & 171 & NM_001001861 & [21] \\
\hline GM-CSF & GAAACCGTAGACGTCGTCTG & GTGCTGCTCATAGTGCTTGG & 62 & 150 & DQ108393 & {$[21]$} \\
\hline$\underline{\text { HPRT1 }}$ & GGACTTGAATCATGTTTGTG & CAGATGTITCCAAACTCAAC & 60 & 91 & DQ815175 & [24] \\
\hline IL1 $\alpha$ & CCCGTCAGGTCAATACCTC & GCAACACGGGTTCGTCTTC & 60 & 170 & NM 214029 & [43] \\
\hline IL6 & ATCAGGAGACCTGCTTGATG & TGGTGGCTTTGTCTGGATTC & 62 & 177 & NM_214399 & [43] \\
\hline CXCL8 & TCCTGCTITCTGCAGCTCTC & GGGTGGAAAGGTGTGGAATG & 62 & 100 & NM_213867 & [21] \\
\hline IL10 & GGTTGCCAAGCCTTGTCAG & AGGCACTCTTCACCTCCTC & 60 & 202 & NM_214041 & [22] \\
\hline$\underline{\text { RPL19 }}$ & AACTCCCGTCAGCAGATCC & AGTACCCTTCCGCTTACCG & 60 & 147 & AF435591 & {$[21]$} \\
\hline$\overline{\text { TBP-1 }}$ & AACAGTTCAGTAGTTATGAGCCAGA & AGATGTTCTCAAACGCTTCG & 60 & 153 & DQ845178 & [24] \\
\hline TGF $\beta$ & GAAGCGCATCGAGGCCATTC & GGCTCCGGTTCGACACTTC & 64 & 162 & NM 214015 & [21] \\
\hline TLR4 & TGTGCGTGTGAACACCAGAC & AGGTGGCGTTCCTGAAACTC & 62 & 136 & NM_001113039 & [21] \\
\hline TLR2 & ACGGACTGTGGTGCATGAAG & GGACACGAAAGCGTCATAGC & 62 & 101 & NM_213761 & [21] \\
\hline TNF $\alpha$ & CCAATGGCAGAGTGGGTATG & TGAAGAGGACCTGGGAGTAG & 62 & 116 & X54859 & [21] \\
\hline
\end{tabular}

Reference genes are underlined

described by Pilon et al., [26] with few modifications. Briefly, peripheral blood monocytes (PBMC) were isolated by centrifugation $(1000 \mathrm{~g} \times 30 \mathrm{~min})$ over Ficoll ( $d=1.077$, Histopaque, Sigma-Aldrich). Red blood lysing solution (Sigma-Aldrich) was used to remove remaining erythrocytes. Then, cells were resuspended in RPMI glutamax (Gibco, Invitrogen) containing $2.5 \%$ FBS, $1 \%$ Pen/strep and $50 \mu \mathrm{M}$ of $2-\beta$-mercaptoethanol (Sigma-Aldrich). Next, $150 \times 10^{6}$ cells $/ 20 \mathrm{~mL}$ were plated in $150 \mathrm{~cm}^{2}$ cellBind flasks (Corning, Afora, Spain) and incubated for $30 \mathrm{~min}$ at $37^{\circ} \mathrm{C}$ and $5 \% \mathrm{CO}_{2}$. Then, flasks were washed with RPMI to remove all non-adherent cells (lymphocytes). To induce differentiation, monocytes were cultured with RPMI glutamax media containing 1\% Pen/Strep antibiotic, 10\% FBS, $50 \mu \mathrm{M} \beta$ mercaptoethanol and swine recombinant cytokines IL4 (100 ng/mL) and GM-CSF (20 ng/mL) (Biosource, Invitrogen) for 6 days at $37^{\circ} \mathrm{C}$ and $5 \% \mathrm{CO}_{2}$. On day 3, fresh medium and cytokines were added at the same concentrations as previously.

\section{Dendritic cell phenotyping}

After 6 days of culture, cells showed typical DC cell morphology, defined by large cytoplasmic cell mass and long dendrites. In addition, DCs were characterised as CD172a ${ }^{+}$(SWC3), SLA class II-DQ ${ }^{+}$, SLA class II-DR ${ }^{+}$, CD80/86 ${ }^{+}, \mathrm{CD} 14^{\mathrm{mod}}$ and CD11R1 ${ }^{-}$. Antibodies for cell surface markers CD172a/SWC3, SLA class II -DQ, SLA class II-DR and CD11R1 were provided by Dr J. Domínguez (INIA, Madrid, Spain). Antibody for CD14 determination was purchased from Acris Antibodies (AntibodyBCN, Barcelona, Spain) and for CD80/CD86 we used recombinant human Cytotoxic T-lymphocyte associated molecule-4/Fc fusion protein (CTLA4-Fc IgG1, Invitrogen). The FITC-conjugated anti-human immunoglobulin IgG1 or Zenon tricolor mouse IgG1 and IgG2a labelling kits (Invitrogen) were used for detection by flow cytometry (FACSCanto ${ }^{\mathrm{TM}}$ using FACSDiva $^{\mathrm{TM}}$ software; BD Biosciences, San José, California, USA).

\section{Pathogen induced dendritic cell activation}

After 6 days of culture, DCs were recovered and adjusted to $5 \times 10^{5}-1 \times 10^{6} \mathrm{DC} /$ well into 24 -well plates. Then, DCs were incubated with $S c b(\mathrm{MOI}=3)$ or $\beta \mathrm{GM}$ $(10 \mu \mathrm{g} / \mathrm{mL})$ and challenged with ETEC (MOI = 5). After $3 \mathrm{~h}$ of exposure, supernatants were discarded and cells were collected in Trizol reagent. Isolation of DCs mRNA and gene expression studies was performed as described above.

\section{Statistical analysis}

All statistical analyses were performed using PROC GLM by SAS Software version 9.1.3 (SAS institute, Carey, NC, USA). Means for adhesion percentages, mRNA and protein secretion were considered in a 
factorial design $2 \times 3$ ( 2 infection level * 3 experimental treatments) with Duncann post-test grouping for analysis. The $P$ value $\leq 0.05$ was considered to be significant.

\section{Results}

\section{Bacterial adhesion}

Adherence of ETEC on cell membrane of IPI-2I cells was measured to assess the ability of $S c b$ and $\beta$ GM to block ETEC fimbriae, inhibiting ETEC colonization of the intestinal tract. The adherence of ETEC K88 GN1034 $\left(\sim 5 \times 10^{6}-1 \times 10^{7} \mathrm{CFU}\right)$ on pig intestinal IPI-2I cell line $\left(\sim 1 \times 10^{6}\right.$ cells/well), was approximately $15 \%$ (data not shown). Presence of $S c b$ (MOI = 3, Figure 1a) or $\beta$ GM $(10 \mu \mathrm{g} / \mathrm{mL}$, Figure $1 \mathrm{~b})$ significantly inhibited ETEC attachment to $80 \%$ of control $(p<0.001)$ (Figure 1$)$. These optimal doses of $S c b$ or $\beta$ GM were chosen for the following assays.

\section{Cytokine and chemokine mRNA expression of IPI-2I cells}

To assess the preventive effect of $S c b$ and $\beta G M$ on the early immune response to ETEC, we studied the mRNA expression of several cytokines and chemokines. We also verified that $S c b$ and $\beta G M$ did not induce

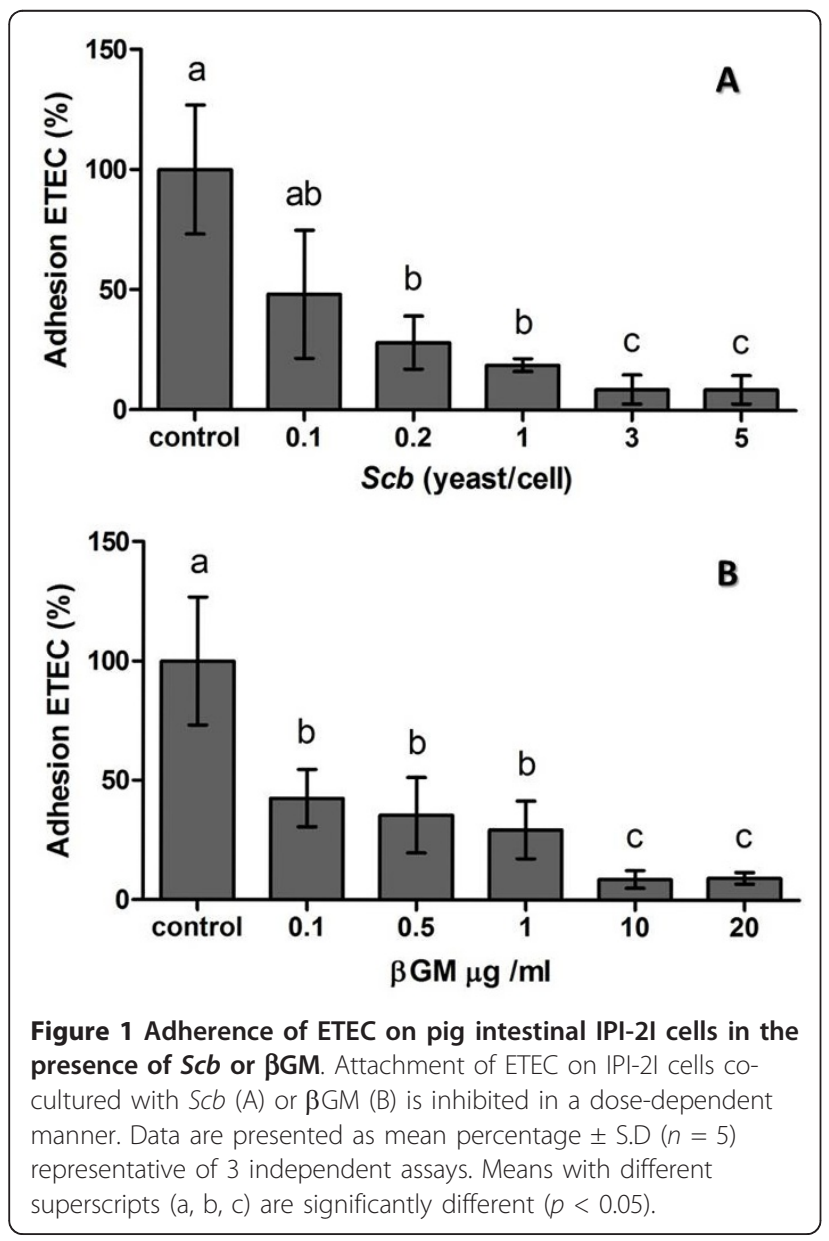

proinflammatory effect per se compared to control cells (Figure 2). As shown in Figure 2, IPI-2I cells cultured with ETEC showed a large up-regulation in the mRNA expression of genes related to inflammation cytokines and chemokines compared to the control group ( $p<$ 0.001 ). The bacterial challenge induced up to 20-fold increase in Tumor Necrosis Factor- $\alpha$ (TNF $\alpha$ ) mRNA levels $(p<0.001)$ and 10-fold higher for chemokine (C-C motif) ligand 20 (CCL20, $p<0.001$ ), whereas the increase was of lower magnitude, between 3- and 6- fold $(p<0.001$, Figure 2) for Granulocyte/Macrophage Colony-Stimulating Factor (GM-CSF), CCL2, CXCL2, interleukins-1 $\alpha$, IL6 and chemokine (C-X-C motif) ligand -2 (CXCL2) and -8 (CXCL8).

The addition of $S c b$ on IPI-2I cells induced a $50 \%$ inhibition of the ETEC-induced mRNA expression of TNF $\alpha$, GM-CSF and CCL20 $(p<0.01)$ (Figure 2). Furthermore, $S c b$ reduced the ETEC-induced mRNA expression for IL1 $\alpha$, IL6, CCL2 and CXCL8 genes to unchallenged control level (Figure 2). Similar to $S c b$, addition of $\beta \mathrm{GM}(10 \mu \mathrm{g} / \mathrm{mL})$ down-regulated the ETEC-induced mRNA expression of TNF $\alpha$, GM-CSF, CCL2, IL6 and CCL20 in infected cells $(p<0.01)$. Inhibition of CXCL8 was smaller in $\beta$ GM treated cells $(\times 1.5, p<0.05$, Figure 2$)$ compared to $S c b(\times 4)$. Finally, $\beta$ GM did not inhibit IL1 $\alpha$ ETEC-induced mRNA.

\section{Cytokine and chemokine secretion}

To confirm the results for the mRNA expression, we studied the protein secretion of cytokine IL6 and chemokine CXCL 8 by ELISA at $24 \mathrm{~h}$ after the infection. Similarly to the mRNA data, neither $S c b$ nor $\beta G M$ showed proinflammatory effects per se and ETEC infection caused a 3.8-fold up-regulation for IL6 concentration $(p<0.01)$ (Figure 3a) and a 1.8-fold increase for CXL8 compared to control wells $(p<0.01)$ (Figure $3 \mathrm{~b})$. Addition of $S c b$ or $\beta G M$ induced between 4- to 10 - fold reduction for IL6 (Figure 3a) and a 1.4-fold decrease for CXCL8 (Figure 3b) $(p<0.05)$ without any statistical difference between both products.

\section{Modulation of mRNA expression of monocyte derived dendritic cells}

Effects of $S c b$ and $\beta$ GM on DCs activation or maturation were determined by the exposure of these products to porcine monocyte-derived DCs with and without ETEC co-culture. The highest pathogen induced DC activation by ETEC was obtained at $\mathrm{MOI}=5$, previously determined by proinflammatory gene expression (mRNA) after $3 \mathrm{~h}$ of co-culture (data not shown). Our results showed that ETEC induced a 2.6 fold-increase of mRNA level of CCR7 and a 4.6 fold up-regulation for TNF $\alpha$ compared to control DC (Figure $4, p<0.01$ ). 


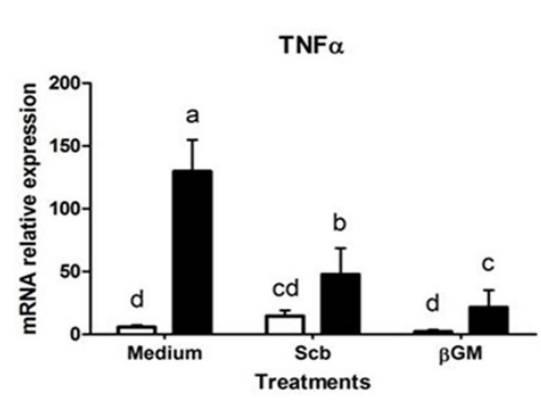

IL1 $\alpha$

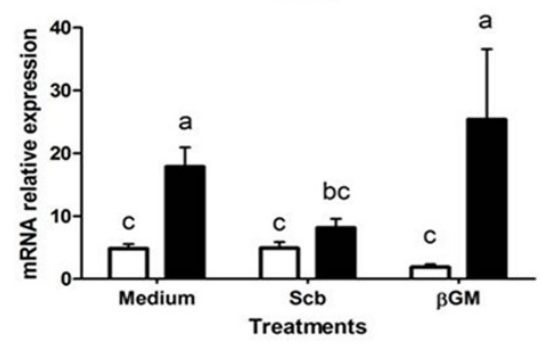

CXCL8

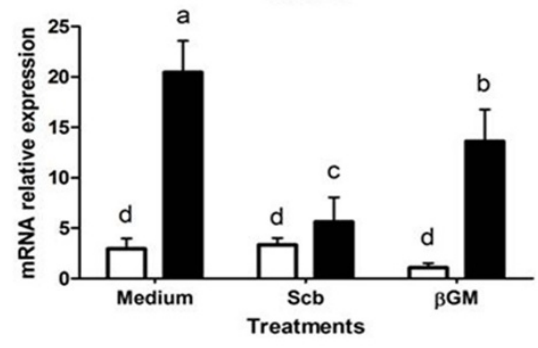

CCL20

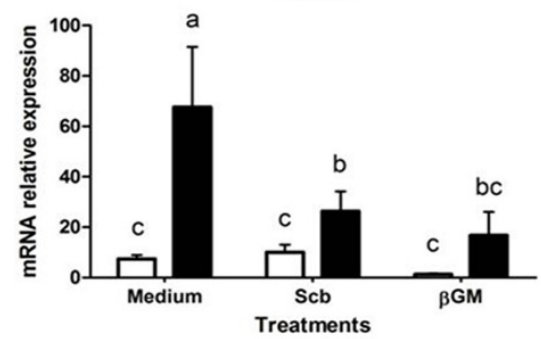

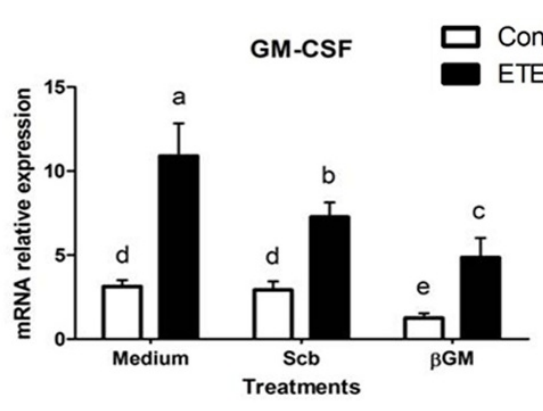

IL6

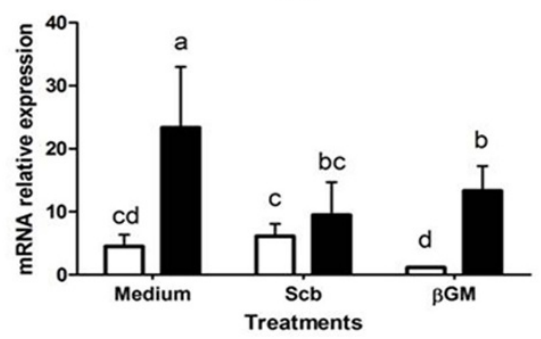

CCL2

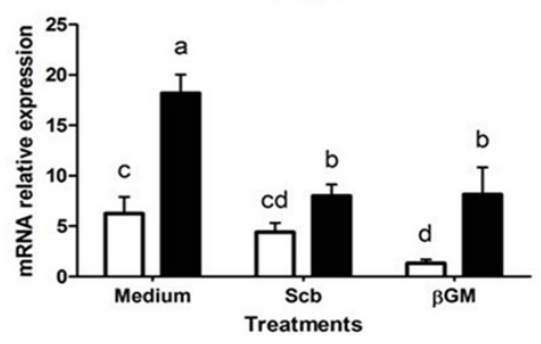

CXCL2

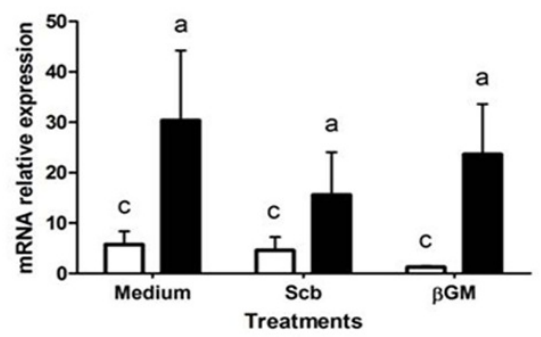

Figure 2 Effects of $S c b$ and $\beta$ GM on cytokine and chemokine mRNA expression in IPI-2I cells cultured with ETEC. IPI-2I cells $\left(1 \times 10^{6}\right.$ cells/well) were co-cultured with $S c b\left(3\right.$ yeast/cell) or $\beta \mathrm{GM}(10 \mu \mathrm{g} / \mathrm{mL})$ with ETEC $\left(1 \times 10^{7}\right.$ CFU/well) for $3 \mathrm{~h}$. Data are presented as means of mRNA relative expressions $\pm S D(n=6)$. Results are representative of 3 independent experiments. Means with different superscripts $(a, b, c, d, e)$ are significantly different $(p<0.0 .5)$.

Gene expression for TLR4, TLR2, B-cell activating factor (BAFF), a proliferation-inducing ligand (APRIL) and CCL17 were between 1.5 and 2 fold-higher in ETECinduced DCs than in unchallenged DCs (Figure $4, p<$ 0.01). The mRNA level for IL6 and GM-CSF were highly up-regulated $(\times 13$ and $\times 26$ respectively) after ETEC co-culture, as well as for IL10 $(\times 6)$ (Figure $4, p<$ 0.001). Therefore, we defined activated DC as high mRNA expression of CCR7 and TLR4 receptors, T-cellindependent IgA class-switch recombination (CSR) modulatory factors BAFF and APRIL; cytokines TNF $\alpha$, IL6, GM-CSF, CCL17 and IL10.

The mere addition of $S c b(\mathrm{MOI}=3)$ or $\beta \mathrm{GM}(10 \mu \mathrm{g} /$ $\mathrm{mL}$ ) triggered a slight but statistically significant up-regulation of TNF $\alpha(\times 2.7$ and $\times 2$ respectively $)$ and CCR7 mRNA $(\times 1.6)$ compared to the control with medium (Figure $4, p<0.05$ ). Both products also enhanced gene expression for GM-CSF $(\times 5$ and $\times 1.6)$. However, only $S c b$ induced gene expression of IL6 $(\times 3.3)$ and IL10 $(\times 2.3)$ (Figure $4, p<0.05)$. 


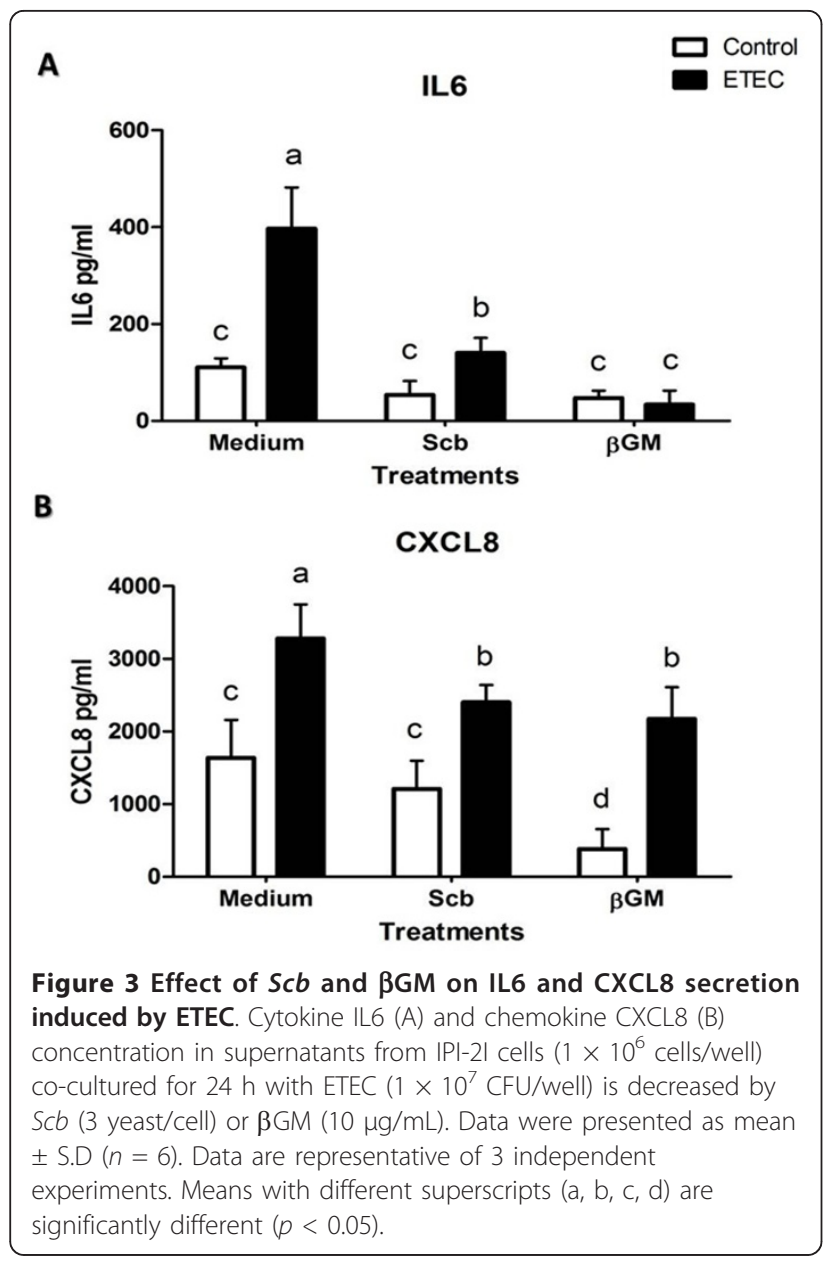

The ETEC-induced mRNA expression of DCs co-cultured with $S c b(\mathrm{MOI}=3)$ or $\beta \mathrm{GM}(10 \mu \mathrm{g} / \mathrm{mL})$ was similar to infected control (Figure 4) for TNF $\alpha$, CCR7, TLR4, TLR2, BAFF, APRIL and TGF $\beta$ genes. Therefore no synergistic or antagonistic effect was observed for these genes related to DCs activation. However, ETECinduced mRNA expression of IL10 and CCL17 was 2.3fold inhibited in $\beta$ GM treated DCs $(p<0.05$, Figure 4$)$.

\section{Discussion}

After European ban of antibiotic growth promoters for animal feeding (EC 1831/2003), probiotics and prebiotics have been postulated as promising alternatives to AGPs in animal feeding [7]. This work studied the effect of a new commercial prebiotic compared to an already proven probiotic on porcine IECs and DCs in the context of an ETEC in vitro infection. Besides to provide selective advantages to microbiota and to exclude pathogens, prebiotics are believed to mimic the host cell receptor which the pathogen adheres. Mannose derivates are described to bind to Type I fimbriae or pili which contains multiple-subunits of lectins that bind to mannan units of the glycoproteins on the surface of host cells [27,28]. In that sense, Shoaf et al. [3], tested several commercially available non-digestible oligosaccharides (NDOs) with different molecular structures. The latter highlighted that galactoligosaccharides had higher inhibition of E.coli adherence on Caco-2 and Hep-2 cells in a dose dependent manner. Similar to NDOs, yeast probiotic properties, such as Saccharomyces cerevisiae, are specie- or strain- specific [29]. The ability of $S c b$ to aggregate enterohaemorrhagic E.coli (EHEC) on their cell wall though type I fimbriae recognition was described by Gedek B. R [30]. However, ETEC K88 bears F4 fimbriae [31], which is described as mannose-resistant in the agglutination test with $0.5 \% \mathrm{D}$-mannose [32]. Nevertheless, all three variants of $\mathrm{K} 88$ adhesin expressed on the tip of the $\mathrm{F} 4$ fimbriae recognize carbohydrate structures expressed on host cell glycoconjugates [33] such as sialoglycoproteins, intestinal mucin-type glycoproteins and neutral glycosphingolipids [34]. Indeed, $\beta$-linked galactose residues have been found to be essential component in the attachment of K88 fimbriae to mucus K88 receptors [35,36]. Our results show that addition of $S c b$ or $\beta$ GM, reduces the adhesion of ETEC on the surface of porcine intestinal epithelial IPI-2I cell approximately to $80 \%$. Together, these data confirm that products highly rich in galactose residues, like our $\beta$ GM and $S c b$, may bind to K88 adhesin [27], suggesting their role as a prophylactic agent to gastrointestinal infections in pigs $[37,38]$.

The enterotoxigenic E.coli K88 (ETEC) in vitro infection causes a proinflammatory transcriptional profile on porcine intestinal cells IPI-2I, upregulating gene expression cytokines TNF $\alpha$, GM-CSF involved in proliferation and activation of neutrophils, IL1 $\alpha$, IL6 (acute phase reactions, proliferation and differentiation of macrophages and B-cells) as well as proinflammatory chemokines CXCL8 (neutrophil recruitment), CCL2 (MCP-1, Monocyte chemotactic protein-1), CXCL2 and CCL20 chemotactic for immature DCs involved in the bacterial uptake across the epithelial barrier. These results are in accordance to results of Eckmann et al., [39], but contrary to data published by Pavlova et al., [4] who found no differences in mRNA expression of cytokine TNF $\alpha$ and chemokine CXCL8 after in vitro attachment of different serotypes of ETEC on IPI-2I cells. However, response of IPI-2I cells under challenge conditions and mRNA expression of genes TNF $\alpha$ and CXCL8 has been already demonstrated in the gene expression study performed by Mariani et al., [40], as well as in different hostpathogen interaction studies where IPI-2I were infected by another Gram negative pathogen as Salmonella [41]; Salmonella lipopolysaccharide (LPS) [42] or even Enteamoeba hystolytica parasite [43]. The explanation for these contradictory results may be due the difference in cell culture conditions (see Mariani et al., [40]) or to the 

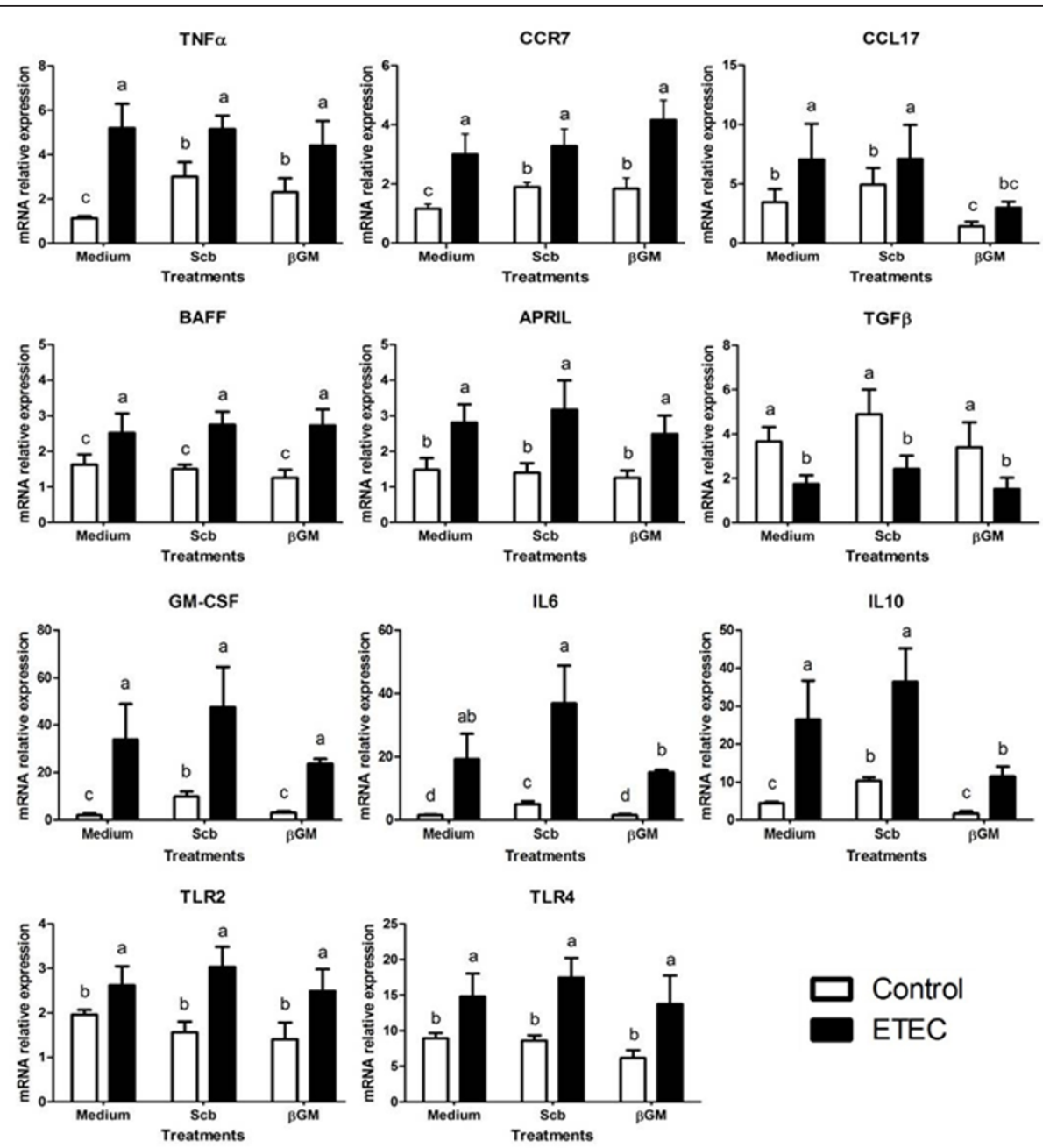

Figure 4 ETEC-induced gene expression in porcine DCs co-cultured with Scb or $\beta$ GM. Relative mRNA expression of proinflammatory cytokines (TNF $\alpha$, GM-CSF, IL6, IL10), chemokines (CXCL8, CCL17), receptors (CCR7, TLR2, TLR4) and regulatory factors (APRIL, BAFF, TGF $\beta$ ) in DCS is enhanced by ETEC. Data were presented as mean \pm S.D $(n=6)$. Treatments with different letters $(a, b, c, d)$ mean $p<0.05$.

specificity of the ETEC serotype used in each study. In our model, presence of ETEC or their bacterial constituents such as LPS or flagellin induces a two to tenfold increase in mRNA expression of proinflammatory genes in IPI-2I cells compared to the non-infected cells. At the protein level, data for IL6 and CXCL8 in infected IPI-2I cells (Figure 3 ) are comparable to protein secretion of pig intestinal IPEC-J2 cells shown by Devriendt et al. [31], as a response of TLR5 signalling cascade upon recognition of ETEC F4 flagellin. Addition of $S c b$ or $\beta$ GM down-regulate ETEC-induced gene expression of TNF $\alpha$, GM-CSF, IL6, CCL2, CXCL2 and CCL20, reducing the overall proinflammatory state caused by ETEC. This effect is not induced for mRNA of IL1 $\alpha$ nor CXCL8 in $\beta$ GM treated cells compared to the $S c b$ treatment, but no difference was shown between IL6 and CXCL8 in the reduction of mRNA or protein expression.
In accordance to current data, probiotic $S c b$ has been shown to secrete anti-inflammatory factors smaller than $10 \mathrm{kDa}$ [44] that have inhibitory effects on mRNA expression of cytokine IL1- $\alpha$, IL6 as well as chemokines CXCL2 and CXCL8 on IPI-2I cells co-cultured with ETEC [18]. These anti-inflammatory properties have been related to direct blocking of nuclear factor-kappa B (NFkB) and mitogen associated protein kinase (MAPK) activation [45] or by indirect neutralization of ETEC toxins [8]. Recently, Zanello et al. [46] demonstrated that Saccharomyces cerevisiae inhibition on proinflammatory transcripts in porcine intestinal cells IPEC-1 cocultured with ETEC was associated to the decrease of ERK1/2 and p38 MAPK phosphorylation. Related to NDOs, beneficial role of $\beta G M$ from partially hydrolyzed guar gum was described to prevent mucosal damage in dextran sulphate sodium (DSS) induced colitis in mice 
[47] by a decrease of TNF $\alpha$ mRNA/protein and neutrophil infiltration. Future studies should determine the role of NDOs and especially $\beta G M$ on the molecular signaling pathways involved in regulation of IECs upon ETEC infection.

Probiotics and prebiotics are believed to be recognized by PRRs expressed on dendritic cells (DCs) located in the subepithelial dome (SED) and/or to extend their dendrites between epithelial cells to the lumen. We aimed to establish if optimal concentrations of $S c b$ or $\beta G M$ for IECs also modulate DC activation or maturation per se and/or under ETEC infection. In our work, brief incubation $(3 \mathrm{~h})$ with $S c b$ or $\beta G M$ induced a slightly activation of DC observed by an up-regulation of mRNA for TNFa and CCR7 coreceptor (Figure 4). Recently, Santander et al. [48] described that long exposure $(\sim 48 \mathrm{~h})$ to $\beta \mathrm{GM}$ from Caesalpinia spinosa plant extracts induce phenotypic maturation of human DC characterized by CD83, CD86, CD206 and HLA-DR and increase mRNA for IL1 $\beta$, IL6, CXCL8 and IL12p70 cytokines.

The ETEC-induced maturation of porcine DCs is mainly induced by flagellin, through Fc $\gamma$ receptor ligation [49], among other bacterial constituents such as F4 and LPS $[49,50]$. We observed that ETEC up-regulated mRNA level of CCR7, receptor for CCL19 and CCL21, which provides DC signal for entry into the inductive sites of the adaptive immune system such as the lymph node. Furthermore, there was an increase in BAFF and APRIL, members of the tumor necrosis factor superfamily involved in T-cell-independent IgA class-switch recombination (CSR). Additionally, ETEC recognition by TLR4 induced up-regulation of this receptor and activated the gene expression of cytokines TNF $\alpha$, GM-CSF, CCL17 and IL6. Finally, IL10 mRNA was increased in challenged DCs, probably to limit over-whelming specific and unspecific immune response and to avoid tissue damage [51]. Although no phenotypic study was performed in this work, published data [50] indicate that porcine monocyte-derived DC are expected to increase cell surface co-stimulatory molecules CD80/C86 and protein TNF $\alpha$, IL6 and CXCL8 secretion after TLR ligand recognition.

In our study, co-incubation of porcine DCs with $S c b$ or $\beta G M$ and ETEC did not trigger significant differences on DCs maturation compared to infected control for the most of the genes studied. In contrast, Sonck et al. [52] found that effects of $\beta$-glucans on DC maturation differ according to their origin, while Saccharomyces cerevisiae derived $\beta$-glucan Macrogard induced mature phenotype determined by upregulation of DC activation markers (CD80/86, CD40 and MHC class II), curdlan enhanced expression of cytokines IL-1 $\beta$, IL-6, IL-10 and IL-12/IL23p40. Related to prebiotics, Wismar et al. [53] found that galactomannans from guar gum at high concentrations $(\sim 200 \mu \mathrm{g} / \mathrm{mL})$ directly stimulate mice DCs and modulate DC maturation induced by microbial signals, such as LPS, leading to a synergistically increased TNF $\alpha$ and IL10 proteins and suppression of IL-12p70. Indeed, Sheng et al. [54] showed that mannan and mannan associated structures activate TLR4 signalling pathways in a dose dependent manner, induce DCs mature phenotype (CD40, CD80 and CD86) and up-regulate proinflammatory mRNA for IL1- $\beta$ and TNF $\alpha$ cytokines as well as other Th1/Th2 cytokines. Considering that origin, structure and size of mannans or $\beta$-glucans is crucial to determine their immune regulatory role [53], differences in product concentration and time exposure may explain our contrary results.

The beneficial role of these products remains to be elucidated on DCs activation under ETEC infection, as well as for other cell types involved in the mucosal immune response, such as monocytes/macrophages or neutrophils. In addition to evaluate $S c b$ and $\beta G M$ in in vivo trials, research approaches as three-dimensional coculture [55] or gut-loop intestinal models [21] may determine effect of $S c b$ and $\beta G M$ on the cross-talk of IECs, DCs and other cell types under ETEC infection.

To summarize, present findings describe the protective role of probiotic Saccharomyces cerevisiae var. Boulardii and a recently developed prebiotic $\beta$-galactomannan, to prevent E.coli $\mathrm{K} 88$ infection using an in vitro model for pig intestinal cells, and consequently their ability to reduce pathogenic inflammation. These results may lead to in vivo trials to assess the suitability of probiotic $S c b$ and prebiotic $\beta \mathrm{GM}$ as alternative to antibiotics growth promoters in animal production.

\section{List of abbreviations}

APRIL: A proliferation-inducing ligand; BAFF: B-cell activating factor; $\beta G M$ : $\beta-$ galactomannan; $\mathrm{CCL}$ : chemokine: $\mathrm{C}-\mathrm{C}$ motif) ligand; $\mathrm{CXCL}$ : chemokine: $\mathrm{C}-\mathrm{X}-\mathrm{C}$ motif) ligand; DCs: Dendritic cells; ETEC: Enterotoxigenic Escherichia coli K88; GM-CSF: Granulocyte/Macrophage Colony-Stimulating Factor; IECs: Intestinal epithelial cells; IL: Interleukin; NDOs: Non-digestible oligosaccharides; PAMPs: Pathogen associated molecular patterns; PRRs: Pattern recognition receptors; Scb (Saccharomyces cerevisiae var. Boulardii; TLR: Toll like receptor; TNFa:

Tumor necrosis factor-a)

\section{Acknowledgements}

This work was supported by grants from the French National Institute for Agricultural Research (INRA, France) and grant AGL 2009-11936 of the Ministerio de Ciencia e Innovación (MICIIN, Spain). We gratefully acknowledge Dr I. Badiola (CReSA) for providing ETEC GN1034 strain and Dr J. Domínguez-Juncal (Instituto Nacional de Investigación y Tecnología Agraria y Alimentaria, INIA, Madrid, Spain) for kindly providing antibodies for pig cell surface markers.

\section{Author details}

${ }^{1}$ Institut de Recerca i Tecnologia Agroalimentàries, Animal Production, IRTA Constantí, Spain. ${ }^{2}$ Institut National de la Recherche Agronomique (INRA), UR1282, Infectiologie Animale et Santé Publique, F-37380 Nouzilly, Tours, France. ${ }^{3}$ Immunologia Aplicada, Institut de Biotecnologia i de Biomedicina (IBB), University Autonomous of Barcelona, UAB, Bellaterra, Spain. 


\section{Authors' contributions}

RB conceived the study and carried out IECs and DCs host cell-pathogen cocultures, molecular studies and immunoassays. GZ participated in IECS host cell-pathogen assays and molecular analysis. CC worked in DCs differentiation and co-culture. RL participated in experimental design and statistical analysis. PM, FM, JB and HS equally conceived, coordinated the study and helped to draft the manuscript. All authors read and approved the final manuscript.

\section{Competing interests}

$J B$ is one of the inventors of the patent Salmosan ${ }^{{ }^{\circledR}}$ WO2009/144070 A2 commercially licensed to Industrial Técnica Pecuaria (ITPSA, Barcelona, Spain). This does not alter the author's adherence to all the Veterinary Research policies on data collection and analysis, preparation of the manuscript or sharing data and materials. Other authors declare that they have no competing interests.

Received: 21 June 2011 Accepted: 25 January 2012 Published: 25 January 2012

Nagy B, Arp LH, Moon HW, Casey TA: Colonization of the small intestine of weaned pigs by enterotoxigenic Escherichia coli that lack known colonization factors. Vet Pathol 1992, 29:239-246.

2. Girard MP, Steele D, Chaignat CL, Kieny MP: A review of vaccine research and development: human enteric infections. Vaccine 2006, 24:2732-2750

3. Shoaf K, Mulvey GL, Armstrong GD, Hutkins RW: Prebiotic galactooligosaccharides reduce adherence of enteropathogenic Escherichia coli to tissue culture cells. Infect Immun 2006, 74:6920-6928.

4. Pavlova B, Volf J, Alexa P, Rychlik I, Matiasovic J, Faldyna M: Cytokine mRNA expression in porcine cell lines stimulated by enterotoxigenic Escherichia coli. Vet Microbiol 2008, 132:105-110.

5. World Health Organisation: The Medical Impact of the use of antimicrobials in food animals. 13-17 October; Berlin, Germany 1997.

6. Brufau J: Animal feeding in Europe: challenges and opportunities. In Nutritional biotechnology in the feed and food industries. Edited by: Lyons TP, Jacques KA. Notthingham University Press; 2003:

7. Gaggia F, Mattarelli P, Biavati B: Probiotics and prebiotics in animal feeding for safe food production. Int J Food Microbiol 2010, 141(Suppl 1): S15-28.

8. Zanello G, Meurens F, Berri M, Salmon H: Saccharomyces boulardii effects on gastrointestinal diseases. Curr Issues Mol Biol 2009, 11:47-58.

9. Morales-López R, Auclair E, García F, Esteve-Garcia E, Brufau J: Use of yeast cell walls; beta-1, 3/1, 6-glucans; and mannoproteins in broiler chicken diets. Poult Sci 2009, 88:601-607.

10. Czerucka D, Piche T, Rampal P: Review article: yeast as probiotics Saccharomyces boulardii. Aliment Pharmacol Ther 2007, 26:767-778.

11. Oswald IP: Role of intestinal epithelial cells in the innate immune defence of the pig intestine. Vet Res 2006, 37:359-368.

12. Summerfield A, McCullough KC: The porcine dendritic cell family. Dev Comp Immunol 2009, 33:299-309.

13. Artis D: Epithelial-cell recognition of commensal bacteria and maintenance of immune homeostasis in the gut. Nat Rev Immunol 2008, 8:411-420

14. Sansonetti PJ: War and peace at mucosal surfaces. Nat Rev Immunol 2004, 4:953-964

15. Cloeckaert A, Schwarz S: Molecular characterization, spread and evolution of multidrug resistance in Salmonella enterica typhimurium DT104. Vet Res 2001, 32:301-310.

16. Kaeffer B, Bottreau E, Velge P, Pardon P: Epithelioid and fibroblastic cell lines derived from the ileum of an adult histocompatible miniature boar (d/d haplotype) and immortalized by SV40 plasmid. Eur J Cell Biol 1993, 62:152-162.

17. Warrand J: Healthy polysaccharides. Food Technol Biotech 2006, 44:355-370.

18. Zanello G, Meurens F, Berri M, Chevaleyre C, Melo S, Auclair E, Salmon H: Saccharomyces cerevisiae decreases inflammatory responses induced by F4+ enterotoxigenic Escherichia coli in porcine intestinal epithelial cells. Vet Immunol Immunopathol 2011, 141:133-138.

19. Elsinghorst EA: Measurement of invasion by gentamicin resistance. Methods Enzymol 1994, 236:405-420

20. Bruel T, Guibon R, Melo S, Guillén N, Salmon H, Girard-Misguich F, Meurens F: Epithelial induction of porcine suppressor of cytokine signaling 2 (SOCS2) gene expression in response to Entamoeba histolytica. Dev Comp Immunol 2010, 34:562-571.

21. Meurens F, Berri M, Auray G, Melo S, Levast B, Virlogeux-Payant I, Chevaleyre C, Gerdts V, Salmon H: Early immune response following Salmonella enterica subspecies enterica serovar Typhimurium infection in porcine jejunal gut loops. Vet Res 2009, 40:5.

22. Levast B, de Monte M, Chevaleyre C, Melo S, Berri M, Mangin F, Zanello G, Lantier I, Salmon H, Meurens F: Ultra-early weaning in piglets results in low serum IgA concentration and IL17 mRNA expression. Vet Immunol Immunopathol 2010, 137:261-268.

23. Meurens F, Berri M, Siggers RH, Willing BP, Salmon H, Van Kessel AG, Gerdts V: Commensal bacteria and expression of two major intestinal chemokines, TECK/CCL25 and MEC/CCL28, and their receptors. PLOS One 2007, 2:e677.

24. Nygard AB, Jørgensen CB, Cirera S, Fredholm M: Selection of reference genes for gene expression studies in pig tissues using SYBR green qPCR. BMC Mol Biol 2007, 8:67.

25. Vandesompele J, De Preter K, Pattyn F, Poppe B, Van Roy N, De Paepe A, Speleman F: Accurate normalization of real-time quantitative RT-PCR data by geometric averaging of multiple internal control genes. Genome Biol 2002, 3, RESEARCH0034.

26. Pilon C, Meurens F, Dauba A, Salmon H, Velge-Roussel F, Lebranchu Y, Baron C: Induction of porcine regulatory cells by mycophenolic Acidtreated dendritic cells. Transplant Proc 2009, 41:700-702.

27. Sharon N: Carbohydrates as future anti-adhesion drugs for infectious diseases. Biochim Biophys Acta 2006, 1760:527-537.

28. Althouse C, Patterson S, Fedorka-Cray P, Isaacson RE: Type 1 fimbriae of Salmonella enterica serovar Typhimurium bind to enterocytes and contribute to colonization of swine in vivo. Infect Immun 2003, 71:6446-6452.

29. van der Aa Kühle A, Skovgaard K, Jespersen L: In vitro screening of probiotic properties of Saccharomyces cerevisiae var. boulardii and foodborne Saccharomyces cerevisiae strains. Int J Food Microbiol 2005, 101:29-39.

30. Gedek BR: Adherence of Escherichia coli serogroup O 157 and the Salmonella typhimurium mutant DT 104 to the surface of Saccharomyces boulardii. Mycoses 1999, 42:261-264.

31. Devriendt B, Stuyven E, Verdonck F, Goddeeris BM, Cox E: Enterotoxigenic Escherichia coli (K88) induce proinflammatory responses in porcine intestinal epithelial cells. Dev Comp Immunol 2010, 34:1175-1182.

32. Nagy B, Fekete PZ: Enterotoxigenic Escherichia coli in veterinary medicine. Int J Med Microbiol 2005, 295:443-454

33. Jin LZ, Zhao X: Intestinal receptors for adhesive fimbriae of enterotoxigenic Escherichia coli (ETEC) K88 in swine-a review. App/ Microbiol Biotechnol 2000, 54:311-318.

34. Sarabia-Sainz Al, Ramos-Clamont G, Candia-Plata MM, Vázquez-Moreno L: Biorecognition of Escherichia coli K88 adhesin for glycated porcine albumin. Int J Biol Macromol 2009, 44:175-181.

35. Payne D, O'Reilly M, Williamson D: The K88 fimbrial adhesin of enterotoxigenic Escherichia coli binds to beta 1-linked galactosyl residues in glycosphingolipids. Infect Immun 1993, 61:3673-3677.

36. Grange PA, Mouricout MA, Levery SB, Francis DH, Erickson AK: Evaluation of receptor binding specificity of Escherichia coli K88 (F4) fimbrial adhesin variants using porcine serum transferrin and glycosphingolipids as model receptors. Infect Immun 2002, 70:2336-2343.

37. Becker PM, Galletti S: Food and feed components for gut healthpromoting adhesion of E. coli and Salmonella enterica. J Sci Food Agric 2008, 88:2026-2035.

38. White LA, Newman MC, Cromwell GL, Lindemann MD: Brewers dried yeast as a source of mannan oligosaccharides for weanling pigs. J Anim SCi 2002, 80:2619-2628.

39. Eckmann L, Kagnoff MF: Intestinal mucosal responses to microbial infection. Springer Semin Immunopathol 2005, 27:181-196.

40. Mariani V, Palermo S, Fiorentini S, Lanubile A, Giuffra E: Gene expression study of two widely used pig intestinal epithelial cell lines: IPEC-J2 and IPI-2I. Vet Immunol Immunopathol 2009, 131:278-284.

41. Volf J, Boyen F, Faldyna M, Pavlova B, Navratilova J, Rychlik I: Cytokine response of porcine cell lines to Salmonella enterica serovar typhimurium and its hilA and ssrA mutants. Zoonoses Public Health 2007, 54:286-293. 
42. Arce C, Ramírez-Boo M, Lucena C, Garrido JJ: Innate immune activation of swine intestinal epithelial cell lines (IPEC-J2 and IPI-2I) in response to LPS from Salmonella typhimurium. Comp Immunol Microbiol Infect Dis 2010, 33:161-174.

43. Meurens F, Girard-Misguich F, Melo S, Grave A, Salmon H, Guillén N: Broad early immune response of porcine epithelial jejunal IPI-2I cells to Entamoeba histolytica. Mol Immunol 2009, 46:927-936.

44. Sougioultzis S, Simeonidis S, Bhaskar KR, Chen X, Anton PM, Keates S, Pothoulakis C, Kelly CP: Saccharomyces boulardii produces a soluble antiinflammatory factor that inhibits NF-kappaB-mediated IL-8 gene expression. Biochem Biophys Res Commun 2006, 343:69-76.

45. Pothoulakis C: Review article: anti-inflammatory mechanisms of action of Saccharomyces boulardii. Aliment Pharmacol Ther 2009, 30:826-833.

46. Zanello G, Berri M, Dupont J, Sizaret PY, D'Inca R, Salmon H, Meurens F: Saccharomyces cerevisiae modulates immune gene expressions and inhibits ETEC-mediated ERK1/2 and p38 signaling pathways in intestinal epithelial cells. PLoS One 2011, 6:e18573.

47. Naito Y, Takagi T, Katada K, Uchiyama K, Kuroda M, Kokura S, Ichikawa H, Watabe J, Yoshida N, Okanoue T, Yoshikawa T: Partially hydrolyzed guar gum down-regulates colonic inflammatory response in dextran sulfate sodium-induced colitis in mice. J Nutr Biochem 2006, 17:402-409.

48. Santander SP, Aoki M, Hernandez JF, Pombo M, Moins-Teisserenc $\mathrm{H}_{\text {, }}$ Mooney N, Fiorentino S: Galactomannan from Caesalpinia spinosa induces phenotypic and functional maturation of human dendritic cells. Int Immunopharmacol 2011, 11:652-660.

49. Devriendt B, Verdonck F, Summerfield A, Goddeeris BM, Cox E: Targeting of Escherichia coli F4 fimbriae to Fcgamma receptors enhances the maturation of porcine dendritic cells. Vet Immunol Immunopathol 2010, 135:188-198.

50. Auray G, Facci MR, van Kessel J, Buchanan R, Babiuk LA, Gerdts V: Differential activation and maturation of two porcine DC populations following TLR ligand stimulation. Mol Immunol 2010, 47:2103-2111.

51. Couper KN, Blount DG, Riley EM: IL-10: the master regulator of immunity to infection. J Immunol 2008, 180:5771-5777.

52. Sonck E, Devriendt B, Goddeeris B, Cox E: Varying effects of different $\beta$ glucans on the maturation of porcine monocyte-derived dendritic cells. Clin Vaccine Immunol 2011, 18:1441-1446.

53. Wismar R, Brix S, Laerke HN, Frøkiaer H: Comparative analysis of a large panel of non-starch polysaccharides reveals structures with selective regulatory properties in dendritic cells. Mol Nutr Food Res 2011, 55:443-454.

54. Sheng KC, Pouniotis DS, Wright MD, Tang CK, Lazoura E, Pietersz GA, Apostolopoulos $\mathrm{V}$ : Mannan derivatives induce phenotypic and functional maturation of mouse dendritic cells. Immunology 2006, 118:372-383.

55. Zoumpopoulou G, Tsakalidou E, Dewulf J, Pot B, Grangette C: Differential crosstalk between epithelial cells, dendritic cells and bacteria in a coculture model. Int J Food Microbiol 2009, 131:40-51.

doi:10.1186/1297-9716-43-4

Cite this article as: Badia et al: Effect of Saccharomyces cerevisiae var. Boulardii and $\beta$-galactomannan oligosaccharide on porcine intestinal epithelial and dendritic cells challenged in vitro with Escherichia coli F4 (K88). Veterinary Research 2012 43:4.

\section{Submit your next manuscript to BioMed Central and take full advantage of:}

- Convenient online submission

- Thorough peer review

- No space constraints or color figure charges

- Immediate publication on acceptance

- Inclusion in PubMed, CAS, Scopus and Google Scholar

- Research which is freely available for redistribution

Submit your manuscript at www.biomedcentral.com/submit
Biomed Central 